\title{
MINERALOGIA DE SOLOS COM EXCESSO DE SÓDIO NO ESTADO DO CEARÁ(1)
}

\author{
F. O. B. MOTA ${ }^{(2)} \&$ J . B. OLIVEIRA(3)
}

\begin{abstract}
RESUMO
Foram estudados dois perfis de solos com problemas de sodicidade (Planossolo Solódico e Solonetz-Solodizado), no estado do Ceará, com o objetivo de conhecer a mineralogia das frações areia, silte e argila e os processos de alterações que ocorrem nos respectivos minerais. A areia e o silte grosso foram avaliados por microscopia de polarização e contraste de fase, enquanto o silte fino e a argila foram analisados por difração de raios-X. Utilizou-se, ainda, a microscopia eletrônica de varredura para obtenção de informações complementares sobre as transformações mineralógicas ocorridas nos horizontes dos dois perfis. Verificou-se que o Planossolo Solódico apresenta na fração argila quantidades mais ou menos equivalentes de caulinita e montmorilonita no horizonte 2Btn, o mesmo acontecendo com as proporções de caulinita e vermiculita no horizonte A. Nas outras frações, foram encontrados teores variáveis de quartzo, plagioclásios, hornblenda e biotita. Por sua vez, o SolonetzSolodizado mostrou uma fração argila essencialmente caulinítica ao longo de todo o perfil e com quantidades variáveis de quartzo, feldspato e biotita nas outras frações. Em ambos os perfis, o enriquecimento de argila no Bt resultou essencialmente das alterações "in situ" dos minerais primários intemperizáveis contidos na rocha subjacente. A hipótese de alternância de processos de oxiredução nos horizontes $A$ e, ou, E, em razão da baixa permeabi lidade do horizonte 2Btn, provocando um processo de ferrólise naqueles horizontes, é também uma alternativa de gênese que não pode ser descartada para explicar o alto contraste textural desses solos. O intemperismo da albita e de outros plagioclásios ricos em sódio, o clima semi-árido, e a drenagem impedida são os fatores condicionantes dos percentuais elevados de sódio, observados nos dois pedons. Também nos dois solos, os teores destoantes de quartzo, a geomorfologia da região e a presença de uma linha de pedras separando os horizontes $A$ ou $A+E$ do $2 B$ tn revelam duplicidade de materiais originários.
\end{abstract}

Termos de indexação: caracterização e transformação mineralógica, alcalinidade, região semi-árida.

(1) Parte da Tese de Doutorado do primeiro autor apresentada à Universidade de São Paulo, ESALQ/USP, para obtenção do grau de Doutor em Agronomia - Solos e Nutrição de Plantas. Apresentado no XIII Congresso Latino Americano de Ciência do Solo, SoloSuelo em Águas de Lindóia (SP), 1996. Recebido para publicação em setembro de 1997 e aprovado em agosto de 1999.

(2) Professor do Departamento de Ciências do Solo, Universidade Federal do Ceará. CEP 60455-760 Fortaleza (CE).

(3) Professor visitante do Departamento de Água e Solo, Faculdade de Engenharia Agrícola, UNICAMP. CEP 13081-970, Campinas (SP). Bolsista do CNPq. 


\title{
SUMMARY: MINERALOGY OF SODIC SOILS IN CEARÁ
}

\begin{abstract}
Sand, silt and clay fraction mineral ogy as well as theweathering processes of two soils with excess of sodium (SPL and SS) were studied in the state of Ceará, Brazil. The sand coarse and silt werestudied using polarized microscopy and phase contrast, whilethe fine silt and clay wereanalyzed by X-ray diffraction. Additional information on themineralogical transformations that occurred in the horizons of both pedons was obtained using scanning electron microscopy. The Solodic Planosol showed in the clay fraction almost equivalent amounts of kaoliniteand montmorillonitein the $2 \mathrm{Btn}$ horizon, thesameoccurring with the proportions of kaolinite and vermiculite in the A horizon. In the other fractions, variable contents of quartz, plagi oclase, hornblende and biotite werefound. On the other hand, the Solodized-Sol onetz had essentially kaol init clay fraction all over the profile, with variable contents of quartz, feldspar and biotite in the other fractions. In both profiles, the clay enrichment of the argillic horizon seemed to be a result of the weathering of the primary minerals from the underlying parent material. The assumption of alternate oxi-reduction processes in the A and, or, E horizons due to the low 2Btn horizon permeability, which induces a process of ferrolysis on those horizons, is al so an al ternativegenesis which cannot bedisregarded to explain the high textural contrast of these soils. Theweathering of al bite, as well as of the other plagiodases rich in sodium, associated with the semi-arid climate and impeded drainage, are the factors that cause the high sodium percentage observed on both pedons. Also on both soils, the contrasting quartz contents, the geomorphol ogy of the region and thepresence of a stonelineseparating the A or A +E horizons from the2Btn one, reveal a duplicity of parent materials.
\end{abstract}

Index terms: mineral ogical transformations, alkalinity, semi-arid region.

\section{INTRODUÇÃO}

Sol os com problemas de sodicidade, entre os quais estão incluídos os Solonetz-Solodizados (SS) e os Planossolos Solódicos (PLS), objeto do presente trabalho, ocorrem em várias partes dogloboterrestre e sua utilização adquire maior relevância, considerando a necessidade do aumento da área cultivada destinada à produção agrícola (Coelho, 1985).

A região semi-árida do Nordeste Brasileiro, em virtude das características de clima, relevo, geologia e drenagem, entre outros fatores, apresenta condições favoráveis à ocorrência de solos afetados por excesso de sódio e, ou, sais.

No estado do Ceará, em aproximadamente 13.000 km², ocorrem associações de solos, com predominância da classe Planossolo Solódico, e, em outros 8.900 km², ocorrem associações onde predominam as classes dos Solonetz-Solodizados e Solonchak-Sol onétzicos. E m conjunto, essas associações representam $14,8 \%$ da área do estado do Ceará e 9,4\% da superfície de sete estados do Nordeste (Pereira, 1983).

No semi-árido cearense, os sol os são originados, em sua maioria, de rochas cristalinas, com grande predominância de gnaisses e, normalmente, apresentam horizontes $\mathrm{A}$ e, ou, $\mathrm{A}+\mathrm{E}$ de natureza pedimentar (Brasil, 1973). Mineralogicamente, são solos pouco intemperizados com ocorrência de feldspatos potássicos, plagioclásios calco-sódicos e argilominerais montmorilonita e mica (Moreira, 1979). Batista (1988) encontrou em tais solos, no semi-árido do estado da Paraíba, também a presença de vermiculita e caulinita. Luz et al. (1992), estudando Planossolos Solódicos no semi-árido pernambucano, verificaram que transformações de biotitas em vermi culitas, e destas em esmectitas são processos comuns. Observaram, ainda, uma diminuição de esmectita eum aumento de caulinita na direção dos horizontes superficiais.

E m razão da carência de pesquisas mineralógicas em solos do estado e da região Nordeste do Brasil como um todo, o objetivo deste trabal ho foi estudar a mineralogia e as transformações mineralógicas ocorridas nas diversas frações granulométricas de dois perfis de solos com problemas de excesso de sódio, visando contribuir para mel hor conhecimento das potencialidades e limitações desses solos.

\section{MATERIAL E MÉTODOS}

Foram selecionados dois perfis de solos com problemas de excesso de sódio do estado do Ceará, correspondendo a um Planossolo Solódico (PLS) e um Solonetz-Solodizado (SS), localizados, respectivamente, na Zona Fisiográfica do Sertão do 
Sudoeste, em clima semi-árido, e nolitoral em clima subúmido transicional para semi-árido, ambos sob vegetação de caatinga hiper xerófila (Brasil, 1973), e ocorrentes em área de rel evo plano/suave ondulado. Os perfis foram descritos de acordo com Lemos \& Santos (1984), com a nomenclatura dos horizontes seguindo as normas da EMBRAPA (1988).

Litologicamente, os solos estão associados com gnaisse do Pré-Cambriano I ndivisoe, geomorfologicamente, com a Superfície de A plainamento Sertaneja, desenvolvida em decorrência de processos de pediplanação influenciados por clima seco (Souza, 1975).

As análises de alguns atributos físicos (análise granulométrica e argila dispersa em água) e químicos (pH em água, complexo sortivo, CTC, Ki) para caracterização e classificação dos solos, foram feitas no laboratório de solos da U niversidade Federal do Ceará, segundo métodos da EMBRAPA (1979). Na análisegranulométrica, a fraçãoterra fina ( $<2 \mathrm{~mm}$ ) foi dispersada com $\mathrm{NaOH} 1 \mathrm{~mol} \mathrm{L-1}$. A areia total foi separada em areia grossa e fina por peneiramento, enquanto o fracionamento do silte e a separação deste da argila foi feita por sedimentação.

A identificação dos minerais presentes na areia e no silte grosso foi feita por microscopia ótica de pol arização e contraste de fase, em preparados destas frações, segundo Troger (1969) e Gebhardt et al. (1967). A quantificação das fases minerais, neste caso, foi realizada por contagem de grãos, com a estimativa de cada espécie mineral feita em \% de peso da terra fina. Para uma identificação mais precisa das espécies minerais, foram utilizados ainda difratogramas do pó das partículas. Para os feldspatos, usou-se também a técnica de coloração com hexacobal tonitrito de sódio. As frações siltefino eargila foram analisadas por difratometria de raios$X$, em amostras orientadas e na forma de pó, após el iminação da matéria orgânica e dos óxidos de ferro, segundo J ackson (1969), seguida da saturação com potássio e magnésio. Nos tratamentos com potássio, os difratogramas foram obtidos em amostras submetidas à temperatura ambiente e, após, aquecidas a 350 e $550^{\circ} \mathrm{C}$ por $2 \mathrm{~h}$. Os tratamentos com magnésio foram analisados à temperatura ambiente e após adição de etileno gl icol . Para tanto, utilizou-se um equipamento de raios-X Philips micro 1130, dotado de tubo de cobree filtro deníquel.

Para obtenção de informações complementares das transformações mineralógicas ocorridas, frações granulométricas selecionadas dos dois perfis foram ainda examinadas por microscopia eletrônica de varredura, utilizando-se equipamento REM Zeiss 940.

A avaliação semiquantitativa dos minerais das frações mais finas foi obtida por meio do cál culo das áreas dos pi cos dos difratogramas: a montmorilonita, pela área do pico de $1,4 \mathrm{~nm}$ na amostra $\mathrm{K} 25^{\circ} \mathrm{C}$, dividida por 2; a caulinita, pela área do pico de
$0,35 \mathrm{~nm}$ na amostra $\mathrm{K} 350^{\circ} \mathrm{C}$, e a vermiculita, pela área do pico de 1,4 nm na amostra $\mathrm{Mg}$ glicolada, menos a área do pico na amostra $\mathrm{K} 350^{\circ} \mathrm{C}$, dividida por 2 (J ohns et al., 1954). A identificação qualitativa foi feita segundo Brindley (1955); J ackson (1969) e Brown (1961).

\section{RESULTADOSE DISCUSSÃO}

\section{Atributos físicos e químicos}

Os quadros 1 e 2 mostram al guns dos principais atributos físicos e químicos dos solos pesquisados. Ambos os perfis apresentam textura arenosa/média, com alto incremento de argila dos horizontes $\mathrm{A}$ e, ou, E para o2Btn, suficientes para caracterizar uma mudança textural abrupta. Os teores de areia são mais baixos eos de silte expressivamente mais altos no Solonetz-Solodizado, fator possivelmente responsável pelo menor grau de estruturação desse solo em relação ao Planossolo Solódico (PLS). As elevadas quantidades de argila dispersa em água, principalmente no horizonte 2Btn dos dois perfis, são decorrentes da el evada percentagem de sódio trocável no complexo de troca, acarretando baixo grau de floculação das argilas, e contribuem para a manutenção de condições físicas desfavoráveis desses sol os, notadamente quanto à permeabilidade à água e ao desenvolvimento de raízes.

O conteúdo total de bases, em valores absolutos, é relativamente baixo nos horizontes superficiais desses solos, sendo maior no PLS. Enquanto neste as quantidades são suficientes para garantir alta saturação por bases, o SS é epidistrófico. No horizonte 2Btn dos dois solos, a soma de bases e a saturação por bases são mais altas. O incremento no valor desses parâmetros em profundidade acompanha, aproximadamente, o crescimento nos teores de argila dos perfis.

A reação do solo éligei ramenteal cal ina eal calina nos horizontes subsuperficiais do PLS eligeiramente alcalina epraticamente neutra noSS. N os horizontes superficiais dos dois solos, entretanto, a reação é ácida, com valores de $\mathrm{pH}$ acompanhando a variação na saturação por bases. No SS, os menores valores de soma de bases, saturação por bases e pH em relação ao PLS podem ser explicados pela mai or taxa de lixiviação sofrida pelo primeiro, graças à sua ocorrência em ambiente mais úmido. A percentagem de saturação por sódio no horizonte 2Btn dos dois sol os apresenta val ores compatíveis com a definição do caráter solódico do Planossolo e com o conceito central da classe do Solonetz-Solodizado (Brasil, 1973). A relação molecular sílica/alumina, expressa pelo índiceKi, indica menor grau de evolução do PLS em relação ao SS, o que está de acordo com a mineralogia da fração mais fina, discutida a seguir, bem como com as diferenças nas condições ambientais onde ocorrem. 
Quadro 1. Atributos físicos dos perfis de Planossolo Solódico (PLS) e de Solonetz Solodizado (SS)

\begin{tabular}{|c|c|c|c|c|c|c|c|c|c|c|c|}
\hline \multirow[b]{2}{*}{ Solo } & \multirow[b]{2}{*}{ Horizonte } & \multirow[b]{2}{*}{ Profundidade } & \multicolumn{6}{|c|}{ Frações granulométricas da terra fina $(\mu \mathrm{m})$} & \multirow[b]{2}{*}{ G.F } & \multirow[b]{2}{*}{$\begin{array}{c}\text { Relação } \\
\text { silte/argila }\end{array}$} & \multirow[b]{2}{*}{$\begin{array}{c}\text { Classe } \\
\text { textural }\end{array}$} \\
\hline & & & $\begin{array}{c}\text { Areia } \\
\text { grossa e } \\
\text { média } \\
(>200)\end{array}$ & $\begin{array}{c}\text { Areia } \\
\text { fina } \\
(200-53)\end{array}$ & $\begin{array}{c}\text { Silte } \\
\text { grosso } \\
(53-20)\end{array}$ & $\begin{array}{c}\text { Silte } \\
\text { fino } \\
(20-2)\end{array}$ & $\begin{array}{c}\text { Argila } \\
(<2)\end{array}$ & $\begin{array}{c}\text { Argila } \\
\text { natural }\end{array}$ & & & \\
\hline & & $\mathrm{cm}$ & & & & $\%$ & & & & & \\
\hline PLS & $\begin{array}{l}\mathrm{A} \\
2 \mathrm{Btn} \\
2 \mathrm{Cr}\end{array}$ & $\begin{array}{l}0-25 \\
25-58 \\
58^{+}\end{array}$ & $\begin{array}{l}270 \\
280 \\
450\end{array}$ & $\begin{array}{l}450 \\
300 \\
350\end{array}$ & $\begin{array}{l}50 \\
20 \\
10\end{array}$ & $\begin{array}{r}110 \\
120 \\
90\end{array}$ & $\begin{array}{l}120 \\
290 \\
100\end{array}$ & $\begin{array}{r}100 \\
260 \\
80\end{array}$ & $\begin{array}{l}17 \\
10 \\
20\end{array}$ & $\begin{array}{l}1,3 \\
0,5 \\
1,0\end{array}$ & $\begin{array}{l}\text { F. aren. } \\
\text { F.A.aren. } \\
\text { Aren. F. }\end{array}$ \\
\hline SS & $\begin{array}{l}A \\
E \\
2 B t n \\
2 C B\end{array}$ & $\begin{array}{c}0-15 \\
15-32 \\
32-62 \\
62-80^{+}\end{array}$ & $\begin{array}{r}120 \\
50 \\
120 \\
130\end{array}$ & $\begin{array}{l}540 \\
420 \\
280 \\
470\end{array}$ & $\begin{array}{l}210 \\
320 \\
210 \\
220\end{array}$ & $\begin{array}{r}50 \\
120 \\
90 \\
100\end{array}$ & $\begin{array}{r}80 \\
90 \\
320 \\
50\end{array}$ & $\begin{array}{r}40 \\
40 \\
300 \\
40\end{array}$ & $\begin{array}{r}50 \\
56 \\
6 \\
20\end{array}$ & $\begin{array}{l}3,3 \\
4,9 \\
0,9 \\
6,4\end{array}$ & $\begin{array}{l}\text { F. aren. } \\
\text { Franco } \\
\text { F. arg. } \\
\text { F. aren. }\end{array}$ \\
\hline
\end{tabular}

Quadro 2. Atributos químicos dos perfis de Planossolo Solódico (PLS) e de Solonetz-Solodizado (SS)

\begin{tabular}{|c|c|c|c|c|c|c|c|c|c|c|}
\hline \multirow{2}{*}{ Perfil } & \multirow{2}{*}{ Horizonte } & \multirow{2}{*}{$\mathrm{pH}\left(\mathrm{H}_{2} \mathrm{O}\right)$} & \multicolumn{5}{|c|}{ Cátions trocáveis } & \multirow{2}{*}{$\mathbf{v}$} & \multirow{2}{*}{$\mathrm{Na}$} & \multirow{2}{*}{$\mathbf{K i}$} \\
\hline & & & $\mathrm{Ca}$ & Mg & K & $\mathrm{Na}$ & CTC pH 7,0 & & & \\
\hline & & & \multicolumn{5}{|c|}{$-\mathrm{cmol}_{\mathrm{c}} \mathrm{kg}^{1}$} & \multicolumn{2}{|c|}{ — $\%$} & \\
\hline PLS & $\begin{array}{l}\mathrm{A} \\
2 \mathrm{Btn} \\
2 \mathrm{Cr}\end{array}$ & $\begin{array}{l}5,9 \\
7,7 \\
8,7\end{array}$ & $\begin{array}{r}3,4 \\
12,0 \\
-\end{array}$ & $\begin{array}{l}1,6 \\
4,3 \\
-\end{array}$ & $\begin{array}{l}0,3 \\
0,2 \\
-\end{array}$ & $\begin{array}{l}0,3 \\
1,8 \\
-\end{array}$ & $\begin{array}{r}7,0 \\
20,0 \\
-\end{array}$ & $\begin{array}{l}80 \\
92 \\
-\end{array}$ & $\begin{array}{l}4,3 \\
9,0 \\
-\end{array}$ & $\begin{array}{l}2,61 \\
3,29 \\
4,42\end{array}$ \\
\hline SS & $\begin{array}{l}\mathrm{A} \\
\mathrm{E} \\
2 \mathrm{Btn} \\
2 \mathrm{CB}\end{array}$ & $\begin{array}{l}5,4 \\
5,2 \\
7,9 \\
6,9\end{array}$ & $\begin{array}{l}0,2 \\
0,3 \\
2,0 \\
-\end{array}$ & $\begin{array}{l}0,5 \\
0,5 \\
2,3 \\
-\end{array}$ & $\begin{array}{l}0,2 \\
0,1 \\
0,1 \\
-\end{array}$ & $\begin{array}{l}0,1 \\
0,1 \\
2,4 \\
-\end{array}$ & $\begin{array}{l}2,7 \\
2,8 \\
7,6 \\
-\end{array}$ & $\begin{array}{l}37 \\
36 \\
89 \\
-\end{array}$ & $\begin{array}{c}3 \\
3,6 \\
31,6 \\
-\end{array}$ & $\begin{array}{l}2,37 \\
2,64 \\
2,03 \\
2,34\end{array}$ \\
\hline
\end{tabular}

\section{Mineralogia e transformações mineralógicas}

Os minerais presentes na fração argila dos dois solos são constituídos de vermiculita, caulinita e montmorilonita no PLS (Figura 1) e de caulinita, vermiculita quartzo e plagioclásios (predominantemente albita e andesinita) no SS (Figura 2 e Quadro 3). A proporção relativa entreesses minerais varia nos dois solos nos diferentes horizontes (Quadro 3).

O Planossol o Solódico apresentou na fração argila quantidades mais ou menos equivalentes de caulinita e montmorilonita nos horizontes 2Btn e $2 \mathrm{Cr}$, o mesmo acontecendo com as quantidades de caulinita e vermiculita no A. Nas outras frações, foram encontrados conteúdos variáveis de quartzo, plagioclásios, hornblenda e biotita (Quadro 3). A formação de montmorilonita nos horizontes subsuperficiais do PLS pode está associada à maior restrição de drenagem nesses horizontes e ao clima mais seco da região, garantindo, assim, maior atividade de silício e bases no sistema, oriundos da alteração dos plagioclásios e da hornblenda, que favorecem a formação e persistência de esmectitas (Borchardt, 1989).

O fato de a amostra do horizonte A desse solo não ter sofrido expansão no tratamento com etileno glicol (Figura 1) parece indicar a presença de vermiculitas ou montmorilonitas com ligeira intercalação com polímeros de hidroxi-Al nas entrecamadas (Barnhisell \& Bertsch, 1989), o queé possível, considerando a reação mais ácida e a condição mais lixiviante nesse horizonte.

O Solonetz Solodizado mostrou-se predominantemente caulinítico na fração argila ao longo de todo o perfil, apresentando quantidades menores de vermiculita nos horizontes A, E, e 2CB (Figura 3). 


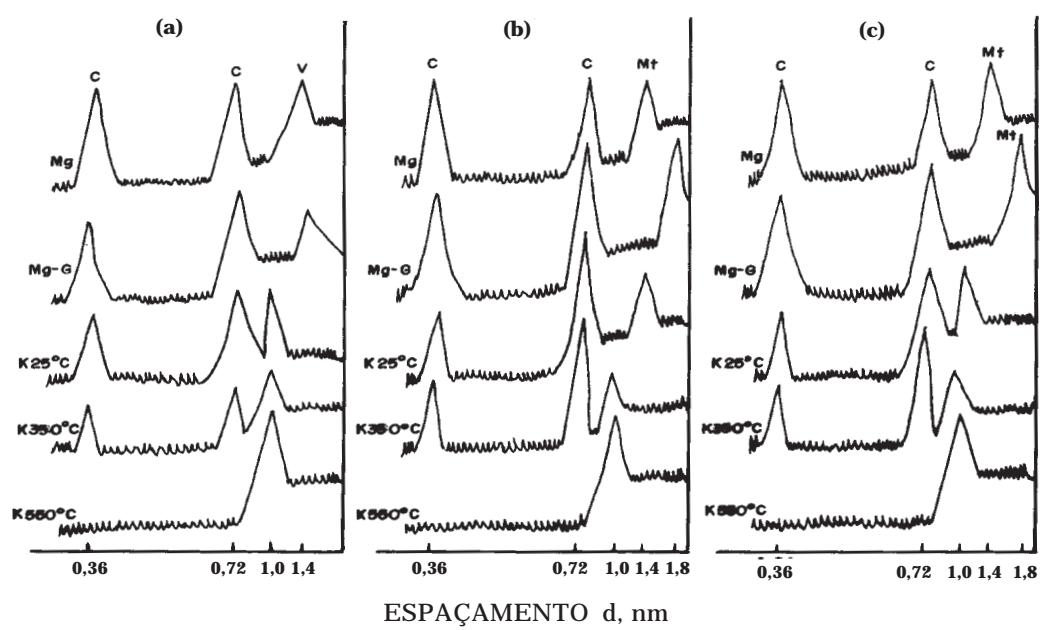

Figura 1. Difratogramas de raios-X da fração argila orientada dos tratamentos com $K$ e aquecimento ( $\mathrm{K} \mathrm{25}, 350$ e $550^{\circ} \mathrm{C}$ ), magnésio $(\mathrm{Mg})$ e magnésio + etileno glicol $(\mathrm{Mg}+\mathrm{G})$ dos horizontes do perfil de Planossolo Solódico: (a) horizonte A; (b) horizonte 2Btn e (c) horizonte 2Cr. (C = caulinita; V = vermiculita e Mt = montmorilonita).

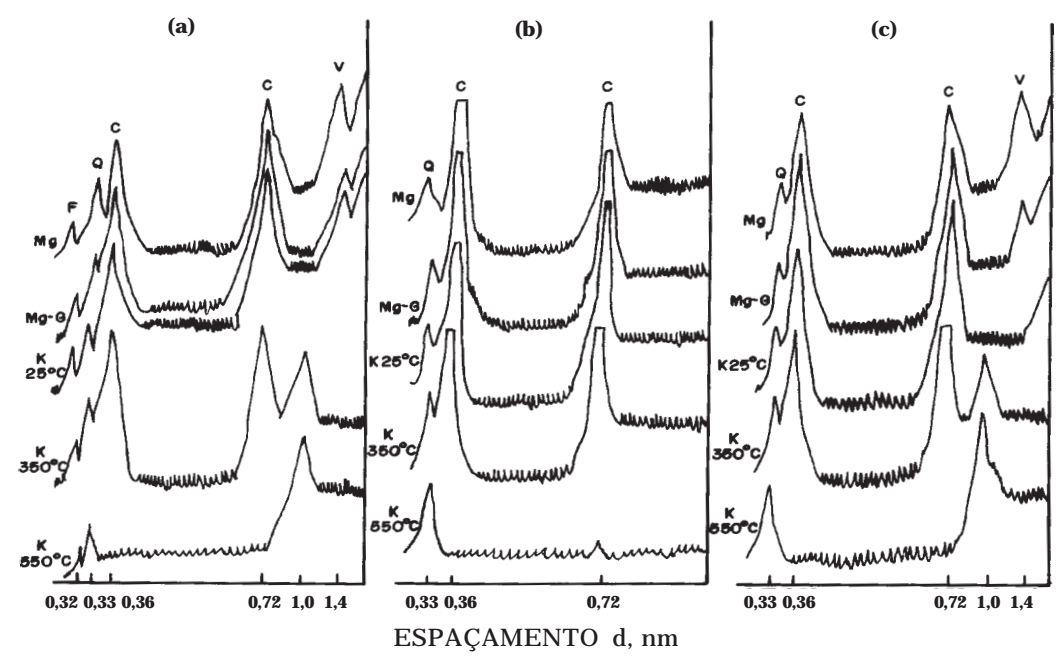

Figura 2. Difratogramas de rai os-X da fração argi la orientada dos tratamentos com $K$ e aquecimento (K 25, 350 e $\left.550^{\circ} \mathrm{C}\right)$, magnésio $(\mathrm{Mg})$ e magnésio + etileno glicol $(\mathrm{Mg}+\mathrm{G})$ dos horizontes do perfil de Solonetz Solodizado: (a) horizonte A; (b) horizonte 2Btn e (c) horizonte 2CB. (C = caulinita; V = vermiculita e $\mathbf{Q}=$ quartzo).

No 2Btn, não foi constatada a presença desse argilomineral, que pareceter-sealterado diretamente para caulinita. O clima mais úmido nessa região, condicionando maiores taxas de lixiviação e intemperismo, pode ter favorecido a formação e, ou, persistência de maiores quantidades de caulinita, a partir do intemperismo de plagioclásios e biotitas, ou mesmo da alteração de vermiculitas. A alteração desse argilomineral diretamente para caulinita também ficou evidenciada por meio de microscopia eletrônica de varredura (dados não mostrados). A vermiculita provavelmente formou-se da alteração das micas trioctaedrais biotita e, ou, flogopita, comuns ainda nas frações mais grosseiras desses solos (Quadro 3).
Segundo Douglas (1989), a vermiculita, com raríssimas exceções, forma-se quase semprea partir do intemperismo das micas, em ambientecom baixo fluxo lixiviante e maior presença de magnésio no sistema. Nas demais frações desse solo, registraramse quantidades variáveis de quartzo, plagiodásios e biotita.

Conformeficou evidenciado, nos dois perfis, foram encontrados minerais facilmente intemperizáveis nas frações areia esilte, o que indica serem tais sol os relativamente pouco intemperizados. A mineralogia da fração argila, por outro lado, é perfeitamente compatível com as diferenças químicas constatadas nos dois solos, ou seja, no PLS, a maior soma debases 
Quadro 3. Componentes mi neralógi cos das frações granulométricas da terra fina dos perfis de Planossolo Solódico (PLS) e Solonetz-Solodizado (SS) identificados e quantificados por análises morfoscópicas e difratometria de raios-X

\begin{tabular}{|c|c|c|c|c|c|c|c|c|c|}
\hline \multirow{2}{*}{ Perfil } & \multirow{2}{*}{ Horizonte } & \multirow{2}{*}{ Profundidade } & \multirow{2}{*}{ Tipo de mineral } & \multicolumn{6}{|c|}{ F rações granulométricas da terra fina ( $\mu \mathrm{m})$} \\
\hline & & & & $>200$ & 200-53 & $53-20$ & 20-2 & $<2$ & $\Sigma$ \\
\hline \multicolumn{10}{|c|}{$\mathrm{g} \mathrm{kg}^{-1}$} \\
\hline \multirow{7}{*}{\multicolumn{2}{|c|}{ A }} & \multirow{7}{*}{$0-25$} & Quartzo & 190 & 370 & 21 & 34 & - & 615 \\
\hline & & & Plagioclásio o(1) & 51 & 32 & 15 & 34 & - & 132 \\
\hline & & & Hornblenda & 14 & 41 & 5 & 5 & - & 65 \\
\hline & & & Biotita $(2)$ & - & - & 4 & - & - & 4 \\
\hline & & & Caulinita & - & - & 3 & 12 & 55 & 70 \\
\hline & & & Vermiculita & - & - & - & 23 & 64 & 87 \\
\hline & & & $\Sigma^{(3)}$ & 255 & 443 & 48 & 108 & 119 & 973 \\
\hline \multirow{16}{*}{ PLS } & \multirow{8}{*}{ 2Btn } & \multirow{8}{*}{$25-58$} & Quartzo & 130 & 210 & 9 & 36 & - & 385 \\
\hline & & & Plagioclásio & 140 & 24 & 3 & 38 & - & 205 \\
\hline & & & Hornblenda & 3 & 18 & 2 & 32 & - & 55 \\
\hline & & & Biotita & - & 12 & 1 & - & - & 13 \\
\hline & & & Caulinita & - & - & - & 6 & 140 & 146 \\
\hline & & & Montmorilonita & - & - & - & - & 150 & 150 \\
\hline & & & Vermiculita & - & - & - & 9 & - & 8 \\
\hline & & & $\Sigma$ & 273 & 264 & 15 & 120 & 290 & 962 \\
\hline & \multirow{8}{*}{$2 \mathrm{Cr}$} & \multirow{8}{*}{$58^{+}$} & Quartzo & 130 & 200 & 4 & 9 & - & 343 \\
\hline & & & Plagioclásio & 200 & 25 & 1 & 13 & - & 239 \\
\hline & & & Hornblenda & 25 & 54 & 2 & 18 & - & 99 \\
\hline & & & Biotita & 90 & 56 & 6 & - & - & 152 \\
\hline & & & Caulinita & - & - & - & 3 & 50 & 53 \\
\hline & & & Montmorilonita & - & - & - & - & 43 & 43 \\
\hline & & & Vermiculita & - & - & - & 43 & 7 & 50 \\
\hline & & & $\Sigma$ & 445 & 335 & 13 & 86 & 100 & 979 \\
\hline \multirow{24}{*}{ SS } & \multirow{6}{*}{$A$} & \multirow{6}{*}{$0-15$} & Quartzo & 98 & 353 & 109 & 40 & 4 & 604 \\
\hline & & & Plagioclásio & 12 & 135 & 59 & 11 & 4 & 221 \\
\hline & & & Biotita & 5 & 13 & 11 & - & - & 29 \\
\hline & & & Caulinita ${ }^{(4)}$ & - & - & 4 & 6 & 56 & 66 \\
\hline & & & Vermiculita & - & - & - & - & 16 & 16 \\
\hline & & & $\Sigma$ & 115 & 501 & 183 & 57 & 80 & 936 \\
\hline & \multirow{6}{*}{$E$} & \multirow{6}{*}{$15-32$} & Quartzo & 35 & 249 & 195 & 58 & 13 & 550 \\
\hline & & & Plagioclásio & 11 & 114 & 58 & 40 & 14 & 237 \\
\hline & & & Biotita & - & 10 & 5 & 6 & - & 21 \\
\hline & & & Caulinita & - & - & 14 & 15 & 45 & 74 \\
\hline & & & Vermiculita & - & - & - & - & 18 & 18 \\
\hline & & & $\Sigma$ & 46 & 373 & 272 & 119 & 90 & 900 \\
\hline & \multirow{6}{*}{ 2Btn } & & Quartzo & 81 & 201 & 67 & 35 & 5 & 384 \\
\hline & & & Plagioclásio & 7 & 20 & 32 & 22 & - & 81 \\
\hline & & & Biotita & 1 & 3 & 9 & 25 & - & 38 \\
\hline & & $32-62$ & Caulinita & - & 54 & 81 & 6 & 308 & 449 \\
\hline & & & Vermiculita & - & - & - & - & - & - \\
\hline & & & $\Sigma$ & 89 & 278 & 189 & 88 & 313 & 952 \\
\hline & & & Quartzo & 83 & 215 & 65 & 40 & 2 & 405 \\
\hline & & & Plagioclásio & 16 & 127 & 40 & 25 & - & 208 \\
\hline & & & Biotita & 17 & 114 & 86 & 28 & - & 245 \\
\hline & $2 \mathrm{CB}$ & $62-80^{+}$ & Caulinita & - & 3 & 7 & 6 & 36 & 52 \\
\hline & & & Vermiculita & - & - & - & - & 11 & 11 \\
\hline & & & $\Sigma$ & 116 & 459 & 198 & 99 & 49 & 921 \\
\hline
\end{tabular}

(1) Predomina albita, até andesinita. (2) Flogopita-biotita. ${ }^{(3)}$ A diferença para 1.000 está associada a minerais pesados, partículas opacas e indeterminadas. ${ }^{(4)}$ Pseudomorfose de bi otita para caulinita com forte incrustação de óxido de ferro, nas frações silte e areia fina. 


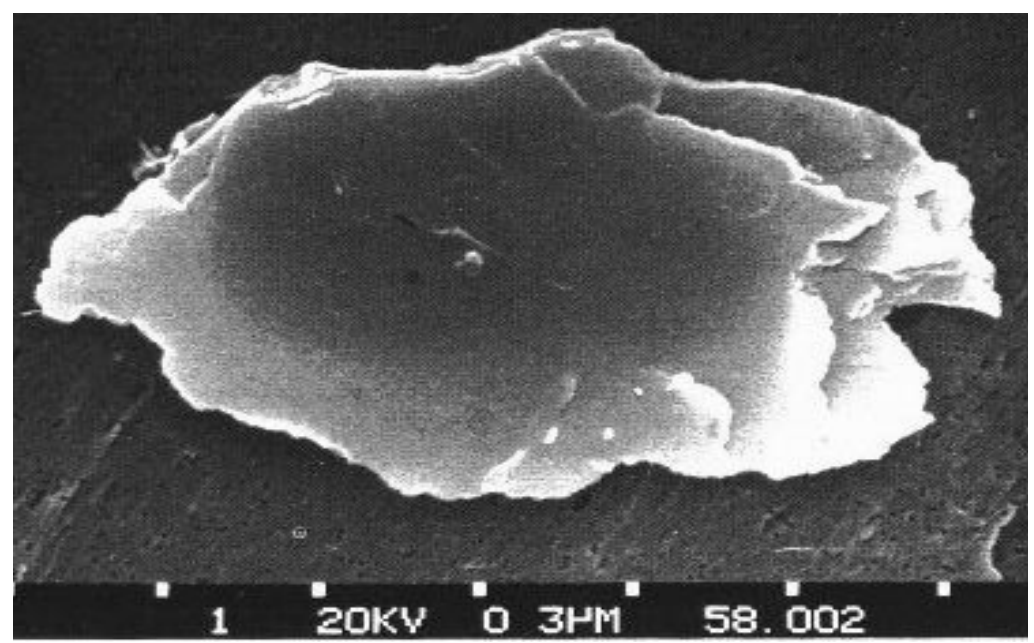

Figura 3. Fotografia obtida por microscopia eletrônica de varredura, mostrando o intemperismo da biotita na fração silte fino no horizonte 2Btn do PLS.

ea CTC estariam relacionadas coma maior quantidade de montmorilonita nesse solo, enquanto a maior pobreza em bases e a menor CTC no SS estariam relacionadas com a maior presença de caulinita.

O enriquecimento de argila no horizonte 2Btn do PLS pode ser explicado, sob o ponto de vista quantitativo, pela decomposição ou transformação de plagioclásios, hornblendas e biotitas, uma vez que, nas frações areia grossa (>200 mm) e areia fina (200-53 mm), os conteúdos desses minerais diminuem de $253 \mathrm{~g} \mathrm{~kg}^{-1}$ do horizonte $2 \mathrm{Cr}$ para o 2Btn, com um conseqüente aumento de caulinita e montmorilonita aproximadamente no mesmo valor $\left(240 \mathrm{~g} \mathrm{~kg}^{-1}\right)$. Assim sendo, em um balanço geral, o enriquecimento de argila no 2Btn pode ser explicado pela decomposição ou transformação dos silicatos primários supracitados. Os teores de quartzo, relativamenteuniformes em $2 \mathrm{Cr}$ e 2Btn e destoantes no $A$, sugerem, em conjunto com uma linha de pedras entre os horizontes A e2Btn, verificada no campo, e a geomorfologia da região, a duplicidade dos materiais originários.

A acumulação de argila no horizonte 2Btn do Sol onetz Sol odizado resulta também, praticamente, da transformação de plagioclásios e biotita. No horizonte 2CB, os totais de plagioclásios e biotita são, respectivamente, 208 e $245 \mathrm{~g} \mathrm{~kg}^{-1}$. No 2Btn, esses números caem para 81 e $38 \mathrm{~g} \mathrm{~kg}^{-1}$, resultando em uma diminuição de cerca de $334 \mathrm{~g} \mathrm{~kg}^{-1}$, com um aumento de argila de $261 \mathrm{~g} \mathrm{~kg}^{-1}$ (Quadro 3). As pequenas quantidades de argila nos horizontes $\mathrm{A} e$ $\mathrm{E}$ parecem não ter origem pedogenética, sendo resultantes principalmente de processos de adição ou acumulação relativos à erosão externa. Por sua vez, os valores divergentes de quartzo e feldspato nesses horizontes revelam a presença de descontinuidadelitológica no perfil, identificada pela presença em campo de uma linha de calhaus e matacỗes de quartzo predominantemente arredondados, tal comojá referido em Brasil (1973).

Portanto, nos dois perfis investigados, a gênese do horizonte $\mathrm{Bt}$, ou seja, o seu enriquecimento em argila, parece resultar essencial mente da alteração de minerais primários "in situ", com o processo de iluviação parecendo ter pouca contribuição, fato esse corroborado pela ausência de cerosidade nos horizontes de máxima acumulação de argila. Resultados semelhantes em condições climáticas idênticas ou similares foram relatados por Alias \& Albaladejo (1978); I sbell (1980), Koppi \& Williams (1980) e Gebhardt (1989). O intemperismo da albita e de outros plagioclásios ricos em sódio, associado com o clima semi-árido, e a forte restrição de drenagem são os fatores condicionantes dos percentuais el evados de sódio observados nos dois pedons (Wilding et al., 1963).

A alternância de processos de oxirredução nos horizontes $\mathrm{A}$ e, ou, $\mathrm{E}$, devida, provavelmente, à baixa permeabilidade do horizonte 2Btn, acarretando um processo de ferról ise naqueles horizontes (Brinkman, 1979), constitui uma alternativa de gênese que não pode ser descartada para explicar o alto contraste textural desses solos, bem como a ausência de vermiculita no horizonte2Btn, que, por ser um mineral maisinstável, seria destruído peloprocesso deferrólise.

A figura 3 mostra uma fotomicrografia da transformação mi neralógica da bi otita sob condi ções de drenagem deficiente. Observa-se que não há uma separação rápida dos óxidos de ferro euma imediata caulinitização, mas, sim, o processo consiste no alargamento do espaçamento basal observado na difração de raios-X, e a formação de montmorilonita, conduzindo ao enriquecimento desse argilomineral no horizonte 2Btn do Planossol o Solódico (PLS). 


\section{CONCLUSÕES}

1. A mineralogia da fração argila é constituída predominantemente de caulinita e montmorilonita no Planossol o Solódico e essencial mente de caulinita no Solonetz-Solodizado, fato esse associado às diferenças de drenagem interna dos dois perfis esuas localizações em mi cror egiões climáticas distintas.

2. A presença dos minerais ( biotita, hornblenda, plagioclásios) considerados de fácil decomposição, nas frações areia e silte dos dois perfis, indica pequeno grau de intemperismo e, ou, maturidade dos sol os estudados.

3. Nos dois perfis investigados, a gênese do horizonte Btn, ou seja, o seu enriquecimento em argila, resulta sugestivamente da alteração de minerais primários "in situ" (hornblendas, plagioclásios e biotita).

4. A presença de linha de pedras separando o(s) horizonte(s) eluvial(ais) do B textural nos dois perfis, associada com a geomorfol ogia da região, revela uma duplicidade de materiais originários na gênese desses solos.

5. O intemperismo da albita e de outros plagioclásios ricos em sódio, associado com o clima semi-árido, e a drenagem deficiente são os fatores condicionantes dos percentuais elevados de sódio observados no horizonte Btn dos dois perfis.

\section{LITERATURA CITADA}

ALIAS, L.J . \& ALBALADEJ O, J . Mineralogia y genesis desuel os com horizonte $B$ textural sobre rocas calizas en el sureste de España. An. Edafol. Agrobiol., 37:647-663, 1978.

BARNHISELL, R.I. \& BERTSCH, P.M. Chlorites and hidroxiinterlayered vermiculite and smectite. In: DIXON, J.B. \& WEED, S.B., eds. Minerals in soil environments. Madison, Soil Science Society of America, 1989. p.729-788.

BATISTA, R.B. Sol os do semi-árido da Paraíba afetados por sódio: mineralogia e síntese de minerais. Viçosa, Universidade Federal de Viçosa, 1988. 129p. (Tese de Doutorado)

BORCHARDT, G.A. Smectites. In: DIXON, J .B. \& WEED, S.B., eds. Minerals in soil environments. Madison, Soil Science Society of America, 1989. p.675-727.

BRASIL. Ministério da Agricultura. Divisão de Pesquisa Pedológica, DNPEA. Levantamento exploratórioreconhecimento de solos do estado do Ceará. Recife, convênios MA/DNPEA-SUDENE/DRN, MA/CONTAP/ USAID/ETA, 1973. 2v. 502p. (Boletim Técnico, 28)

BRINDLEY, G.W. Identification of clay minerals by x-ray diffraction analysis. In: NATIONAL CONFERENCE ON CLAYS AND CLAY TECNOLOGY, 1, San Francisco, 1955. Proceedings. San Francisco, Department of National Resources, 1955. p.119-129.

BRINKMAN, R. Ferrolysis, a soil-forming process in hydromorphic conditions. Wageningen, Pudoc, 1979. 106p. (Agric. Res. Rep. 887)
BROWN, G. The X-ray identification and crystal structures of clay minerals. London, Mineralogical Society, 1961. 544p.

COELHO, M.A. Estudo sobre propriedades físicas de sol os sódicos e salinos sódicos do estado do Ceará. Fortaleza, Universidade Federal do Ceará, 1985. 61p. (Tese de Prof. Titular)

DOUGLAS, L.A. Vermiculites. In: DIXON, J .B. \& WEED, S.B., eds. Mineral in soil environments. Madison, Soil Science Society of America, 1989. p.635-674.

EMPRESA BRASILEIRA DE PESQUISA AGROPECUÁRIA EMBRAPA. Serviço Nacional de Levantamento de Solos. Manual de métodos de análises de solos. Rio de J aneiro, 1979. não paginado.

EMPRESA BRASILEIRA DE PESQUISA AGROPECUÁRIA EMBRAPA. Serviço Nacional de Levantamento e Conservação de Solos. Definição e notação de horizontes e camadas do solo. 2.ed. Rio deJ aneiro,1988. 54p.

GEBHARDT, H. Mineralogy and genesis of soils in semi-arid regions of northeastern-Brazil - The amounts of clay formation and clay translocation in alfisols. Deutschen Bodenkundlichen Gesellschaft., 1:3-10, 1989.

GEBHARDT, H.; MEYER, B. \& SCHEFFER, F. Mineralogische schnelluntersuchung der grobton schluff und fein sandfraktionen von boden mit dem phasenkontrastmikroskop. Zeiss-mitteil, 4:309-322, 1967.

ISBELL, R.F. The argillic horizon concepts and its application to the classification of tropical soils. In: CONFERENCE ON CLASSIFICATION OF TROPICAL SOILS. 1, Kuala Lumpur, 1980. Proceedings. Kuala Lumpur Malasyan Society of Soil Science, p.150-157, 1980.

JACKSON, M.L. Soil chemical analysis: advanced course. Madison, University of Wisconsin, 1969. 895p.

J OHNS, W.D.; GRIM,R. E. \& BRADLEY, W.F. Quantitative estimations of clay minerals by diffraction methods. J . Sedim Petrol., 24:242-251, 1954.

KOPPI, A.J . \& WILLIAMS, D.J . Weathering and devel opment of two contrasting soils formed from granodiorite in southeast Queensland. Aust. J. Soil Res., 18:257-271, 1980.

LEMOS, R.C. \& SANTOS, R.D. Manual de descrição e coleta do solo no campo. Campinas, SBCS/SNLCS, 1984. 46p.

LUZ, L.R.Q.P.; SANTOS, M.C.D. \& MERMUT, A.R. Pedogênese em uma topossequência do semi-árido de Pernambuco. R. Bras. Ci. Solo, 16:95-102, 1992.

MOREIRA, E.G.S. Caracterização e gênese de três pedons de solonetz solodizado do sertão central e médio jaguaribeestado do Ceará. Piracicaba, Escola Superior de Agricultura Luiz de Queiroz, 1979. 83p. (Tese de Doutorado)

PEREIRA, J .R. Solos salinos e sódicos. In: RAIJ, B. van; BATAGLIA, O.C. \& SILVA, N.N., coords. Acidez e calagem no Brasil. Campinas, Sociedade Brasileira de Ciência do Solo, 1983. p.127-143.

SOUZA, M.J.N. Geomorfologia do vale do Choró - CE. Universidade deSão Paulo, 1975. 212p. (Tese deDoutorado)

TROGER, W.E. Optische bestimmung der gesteinsbildenden minerale, teile 1 und 2. Stuttgart, Schweizerbartsche verlagsbuchhandlung, 1969.

WILDING, L.P.; ODELL, R.T.; FEHRENBACHER, J.B. \& BEAVER, A.H. Source and distribution of sodium in solonetzic soils in Illinois. Soil Sci. Soc. Am. Proc., 27:432438, 1963. 